\title{
Control Procedures Support System of Investment Project in the Fuel and Energy Complex on the Basis of Self-Organizing Maps
}

\author{
Bariy Ilyasov \\ Ufa State Aviation Technical University \\ Ufa, Russia \\ ilyasov@tc.ugatu.ac.ru \\ Elena Zakieva \\ Ufa State Aviation Technical University \\ Ufa, Russia \\ zakievae@mail.ru
}

\author{
Elena Makarova \\ Ufa State Aviation Technical University \\ Ufa, Russia \\ ea-makarova@mail.ru \\ Galina Zimina \\ Financial University under the Government of the \\ Russian Federation, Ufa branch \\ Ufa, Russia \\ galina1901@yandex.ru
}

\begin{abstract}
The article deals with the development of the control procedures support system (CPSS) of an investment project in the fuel and energy complex (FEC) based on the use of intelligent technologies. The stages of management of investment projects in a particular fuel and energy company are presented. The estimation of deviations of the actual performance indicators of the project from the planned is presented, the conclusion about the need to use intelligent algorithms of decision-making support in order to reduce risks under uncertainty is made. An approach to solve the problem of development of CPSS of the investment project in the enterprise is proposed. The procedure of neural network data analysis and decisionmaking in the management of the investment project based on the construction of self-organizing Kohonen maps is developed. The examples of the pessimistic and realistic scenarios for managing the implementation of the investment project are presented. It is shown that the timeliness and the correctly chosen sequence of decision-making in time allow for obtaining greater profits, and therefore, achieving the stability in the functioning of the main and investment production and after the completion of the investment project. The developed CPSS of the investment project can be applied at the level of heads of the enterprises as an adviser in the implementation of scenario approach in the management of real investment projects.
\end{abstract}

Keywords-investment project, neural networks, simulation modeling, self-organizing Kohonen maps, decision-making

\section{INTRODUCTION}

The dynamics of global investments in the fuel and energy complex (FEC) and their sectoral structure serve as an important indicator of long-term expectations in terms of demand for basic energy resources. Projects in the FEC, especially in the field of electricity and oil and gas processing, are long-term and require large-scale investments, which imposes additional obligations on investors to determine the parameters of projects and choose among alternative options [1]. It should be noted that energy is one of the priorities of the Russian economy, while the stable development of the electric power industry is an essential condition for the sustainable economic development of the country. Investments in the Russian FEC in 2008-2016, according to the Federal Service for State Statistics, grew continuously, although the growth rate after 2013 decreased. The main growth was provided by the oil and gas sector. In 2016, the total investment in the Russian fuel and energy complex amounted to 3.7 trillion rubles (calculated by the Analytical center on the amount of fuel and energy industries), which is equivalent to $25 \%$ of total investment in the economy and 5 percentage points more than in 2008 [1].

During the monitoring of the Energy strategy of Russia for the period up to 2030, it was noted that the fuel and energy complex should make a significant contribution to the investment support of innovative development of the domestic economy [2].

According to the Ministry of energy of Russia, at the beginning of 2018, the level of physical deterioration of the main equipment of power plants generally corresponds to the assessment of the technical condition "satisfactory" (36\% wear), and the main equipment and power lines of electric networks as a whole corresponds to the type of technical condition "good" (25\%). One of the positive results of the reform is the growth of investments in the field, which allowed to reduce the high degree of wear and tear of the equipment. However, the growth rate of capital investments in the power industry since 2011 is lower than in the country's economy, and the dynamics remains negative [1].

In January 2019, the Russian Government approved the program of modernization of thermal 
power plants (TPP) up to 2031 up to $41 \mathrm{GW}$. The program allows for 10 years to attract 1.9 trillion rubles of private investment in the modernization of TPP and to upgrade a total of $41 \mathrm{GW}$ across the country [3].

Thus, investment is the most important activity in the electric power industry, ensuring the strategic stability of energy supply, that is, reliable and efficient in the long term supply of consumers through technical renovation of production facilities.

At the same time, management decision support systems in the field of investment projects in the energy sector have the following most important and interdependent components that determine the success of investments:

- $\quad$ choosing the optimal investment scheme for a specific energy project;

- $\quad$ choosing a technically competent strategy for the project, taking into account all its individual characteristics.

The solution to the problem of improving the efficiency of investment project management is associated with the need to provide information and analytical support in the decision-making process by the head of the enterprise in order to pre-assess the risks and consequences of decisions in the dynamics. To solve the problem as a whole requires the use of modern information technology, as well as adequate research methods [4-8].

The relevance of the research topic is determined by the need to organize a complex system of analysis, monitoring and decision-making on the implementation of a large-scale investment project in the fuel and energy complex to ensure performance indicators, reduce the level of associated risks of failure to meet deadlines and exceed the budget, as well as compliance of the project with the main strategic objectives of the enterprise.

One of the approaches to improving the efficiency of investment project management is an approach based on the method of simulation modeling, which makes it possible to fully reflect the complex process of implementation of the investment project at the existing enterprise, aimed at updating the production, which is characterized by a large number of parameters, disturbing effects, their random nature and nonlinearity of characteristics. The article proposes a procedure for the implementation of this approach, including the development of dynamic models, intelligent algorithms for decision-making support and of software for information and analytical modeling system (IAMS).

To provide support in decision-making on management of investment processes at the enterprise the information and analytical system of modeling of investment processes on the basis of methods of simulation modeling and neural network technologies is developed [9-12].
The use of this system at the level of heads of the enterprises will reduce the risk in managing the process of implementation of the investment project, since it ensures the application of the scenario approach to quantitative risk analysis.

\section{THE STRUCTURE OF THE IAMS}

The IAMS includes three components: component 1 of simulation modeling; component 2 of experimental data preparation and component 3 of neural network data analysis technologies and decision-making [13-15]. Component 1 of simulation modeling includes a set of dynamic models for the implementation of the investment project, as well as a program for multiple automatic start of the simulation model with different sets of input data.

A number of assumptions were made in the development of a set of dynamic models. We consider the company that produces the main production products, the trajectory of the life cycle of which corresponds to the completion of the maturity stage and the beginning of the aging stage. In this situation, the company, following the strategy of diversification, acquires a loan to launch a new production, called investment production (IP). Demand for new products already exists and is growing. Repayment of the loan is carried out at the expense of funds received from both the investment and the main production. The main purpose of the company's activities in the implementation of the investment project in terms of lending is to obtain planned profit on the main and investment production subject to timely repayment of debt on the loan.

The complex of dynamic models of implementation of the investment project (IPr) in terms of lending contains the following models: M1 model of formation and adjustment of planned rates of resource consumption; M2 model of production and sales of products for primary production; M3 model of production and sales of products for investment production; M4 model of determination of taxes and net profit; M5 model of formation of net cash flow and accumulation of funds; M6 model of loan repayment. The models are developed in a class of discretecontinuous nonlinear models with logical elements and allow to analyze the dynamics of formation, distribution, expenditure and accumulation of funds, as well as repayment of debt on the loan, taking into account the limited amount of accumulated funds. The advantages of the developed models include the possibility, firstly, to simulate the dynamics of the processes of establishing a balance between the flow of consumption and accumulation of funds, taking into account the available reserves; and, secondly, to choose rational management options for different scenarios of the implementation of the investment projects [13-15]. The models are implemented in MATLAB using Simulink application libraries.

Component 2 of the experimental data preparation is designed to form a database of the results of simulation experiments for their subsequent analysis. The component allows to perform: setting the set of 
input and output parameters of the model; automatic formation of combinations of values of input parameters of the dynamic model; setting the set of time points for the analysis of situations; automatic generation of the program text for automatic start of simulation modeling; formation of the database of experimental data on the results of simulation modeling; conversion of the resulting file of the experimental database (ED) in the desired format of the data source for subsequent analysis. This component is implemented in $\mathrm{C}++$ Builder environment, database - in MS SQL environment [13].

Component 3 of neural network technologies for data analysis and decision-making is designed to create a scenario for the analysis of experimental data in order to extract knowledge about the laws of formation of classes of situations in the dynamics and decision-making on the management of the implementation of investment projects using the analytical platform Deductor Studio. The article deals with the procedure of neural network data analysis and the formation of classification rules and decisionmaking for component 3 of the developed IAMS.

\section{FUNCTIONAL SCHEME OF THE MANAGEMENT SYSTEM OF THE PROCESS OF IMPLEMENTATION OF THE INVESTMENT PROJECT}

From the point of view of management, the interaction of dynamic models of the process of implementation of investment project and neural network algorithms of analysis and decision-making is presented in the form of a two-level control system, the functional scheme of which is presented in Fig. 1.

At the lower level of control, three control circuits are highlighted. The first circuit is built on the basis of the feedback principle and solves the problem of operational management of output based on the mismatch between the planned $Y^{0}$ and the actual $Y_{b p}$ and $Y_{i p}$ values of the vectors of controlled coordinates for the main production (MP) and investment production (IP), characterizing the rates and volumes of production. The second feedback control circuit solves the problem of adjusting the consumption of resources for production based on the analysis of the mismatch between the planned $Y_{\text {ent }}{ }^{0}$ and the actual $Y_{\text {ent }}$ values of the vector controlled for the enterprise as a whole, characterizing the volume of savings. The third control circuit solves the problem of calculation and recalculation of payments on $P a y_{c o r}$ loan based on information about the mismatch between the planned amount of payment and available funds.

The control algorithms of the listed circuits of the lower control level are developed in the class of production models, integrated into the dynamic models of component 1 of simulation modeling and operate in automatic and automated modes. The algorithms are presented in procedural form and implemented as special blocks from Simulink application libraries, the logic of which is written in MATLAB [13].

The features of the lower-level control algorithms are as follows. First, it is the use of only a limited set of control actions from the entire possible range of controls. These algorithms are associated with adjusting the flow of cash resources to support either production plans or loan payments. Other control actions, such as price policy, are not considered. Secondly, the adjustment of resource consumption is carried out only within the previously calculated production plans and represents only a forced reduction in resource consumption due to a lack of accumulated funds.

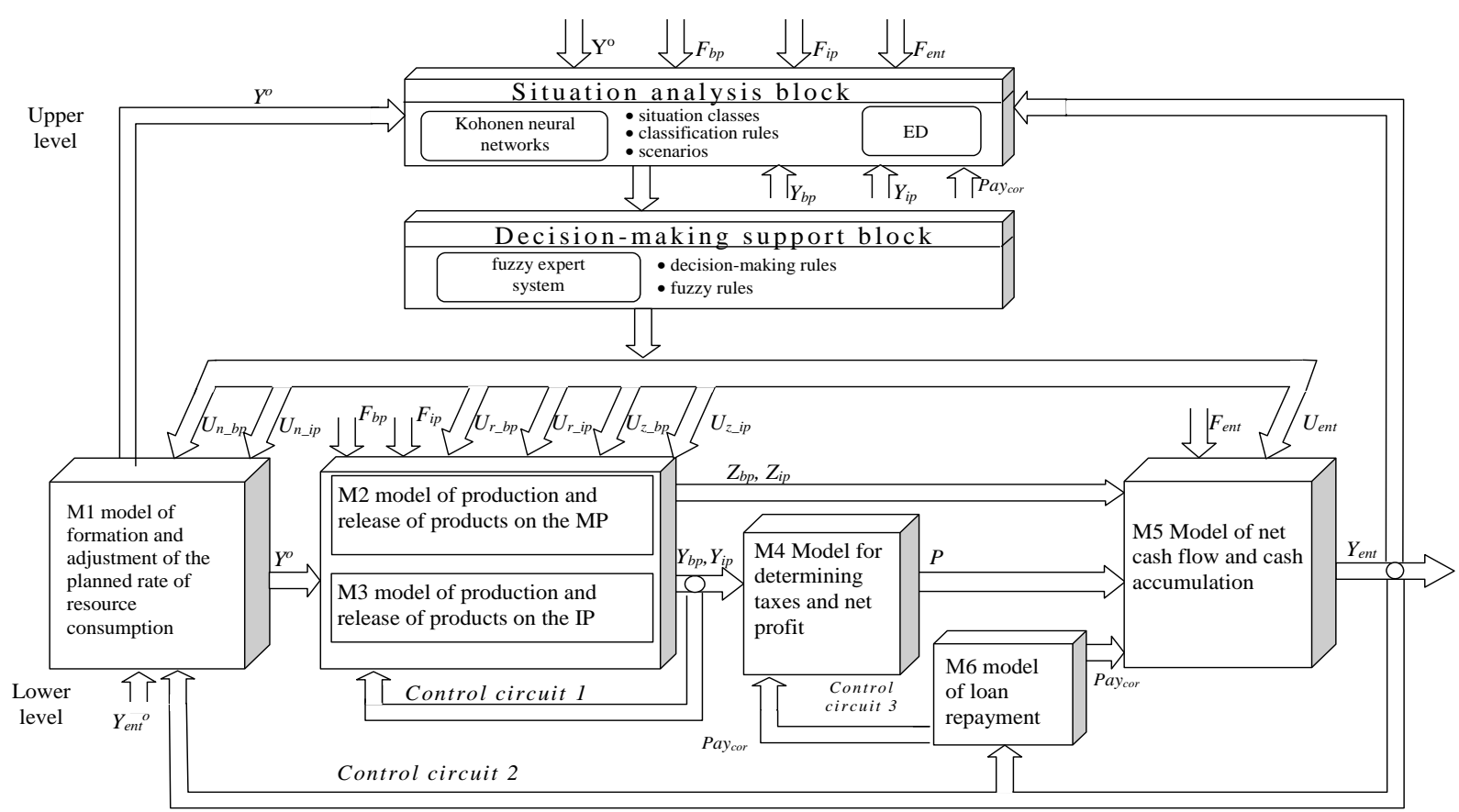

Fig. 1. Functional scheme of the management system of the process of implementation of the investment project 
The recalculation of the plans themselves should be based on the analysis of a large amount of data both on the state of the implementation process of the investment projects, and on external influences from the markets of resources and finished products, as well as on trends in their changes. These decisions, as well as decisions related to the support of products in the markets, are made at a higher level of management.

The upper level of management is based on the principle of situational management and allows to provide support to the decision-maker in the formation of the vector of control actions

$U=\left\langle U_{N_{-} b p}, U_{r_{-} b p}, U_{z_{-} b p}, U_{N_{-} i p}, U_{r_{-} i p}, U_{z_{-} i p}\right.$, $U_{\text {ent }}$ ', where $U_{N_{-} b p}, U_{r_{-} b p}, U_{z_{-} b p}$ - control actions associated with the adjustment of the parameters of the processes of production, sales and formation of cost flows, respectively. For the main production; for investment production the designations are similar and have an index "ip"; $U_{e n t}$ - control actions for the enterprise as a whole, associated with the adjustment, for example, of a loan repayment schedule.

The feasibility of using neural network technologies to solve the problems of top-level management is due to the following reasons. The developed dynamic model for the implementation of investment project is a means of generating new knowledge. The knowledge extraction is carried out by analyzing the results of multiple simulation experiments, which are stored in the database of experimental data. However, the analysis is associated with significant difficulties due to the complexity of the formation of dependencies in the classification of situations and decision-making, as well as the need to process a large number of experimental data as a separate experiment, and for all experiments as a whole [13].

For the purposes of situation analysis and formation of top-level control solutions, it is proposed to apply Kohonen neural networks (NN), the advantages of which include the following. First, the difference between the clustering problem solved by the Kohonen network and the classification problem plays only a positive role here: the absence of the need to know in advance the belonging of the object to any class eliminates the need for the researcher to solve this problem when creating a training sample. Secondly, it is the presence of rich expressive possibilities of visual color mapping of the multidimensional space of experimental data on the plane of self-organizing maps (SOM) in the context of individual features, which allows to quickly give a qualitative assessment of each cluster. Third, it is possible to select areas on the maps that unite: clusters of situations more favorable than planned; clusters of moderately unfavorable situations; clusters of very unfavorable situations corresponding to risk zones. The degree of risk of the current situation can be considered as the degree of its proximity to the risk zone. Application of the Kohonen NN in the context of situational management allows to solve the following tasks: clustering of situations and formation of rules of classification of situations on the basis of multiparameter analysis of the SOM with the help of a decision-maker; definition of clusters related to areas: favorable, moderately unfavorable, very unfavorable (risk zones); formation of decision-making rules based on the identification of the causes of deviation from the desired state by analyzing statistics on the cluster; formation of scenarios of situation development as a means of analyzing the integrated trajectory of the process of implementing the investment project.

\section{PROCEDURE OF NEURAL NETWORK DATA ANALYSIS AND DECISION MAKING IN THE MANAGEMENT OF THE IMPLEMENTATION OF THE INVESTMENT PROJECT}

The procedure of data analysis and decisionmaking for the upper level of control using Kohonen neural networks is proposed [13,16-21]. The generalized scheme of the proposed procedure is shown in Fig. 2. Its features are as follows.

In step 1 , the set of $V$ features that are important for the analysis of situations includes vectors of controlled coordinates $Y_{b p}$ for the main production, $Y_{i p}$ for the investment production and $Y_{\text {ent }}$ for the enterprise as a whole. From the standpoint of the analysis of the dynamics of the implementation of investment project in the composition of these vectors, it is advisable to distinguish three groups of features. These are, first, the rate of formation of costs, revenues, payments (cash flows); secondly, the volume (stocks) of costs, revenues, profits from production; and, thirdly, these are the times of occurrence of special events (for example, the time of Tpp payback of the project).

The presence of step 2 is explained by the fact that the "connection" of the Kohonen network in the circuit of situational management is made at important, from the standpoint of analysis and decision-making, moments of time at the request of the decision-maker. In Fig. 3 the graphs of transient processes of realization of investment projects for the basic experiment (planned mode of realization of investment project) with the indication of the moments of time corresponding to the main events are presented. 


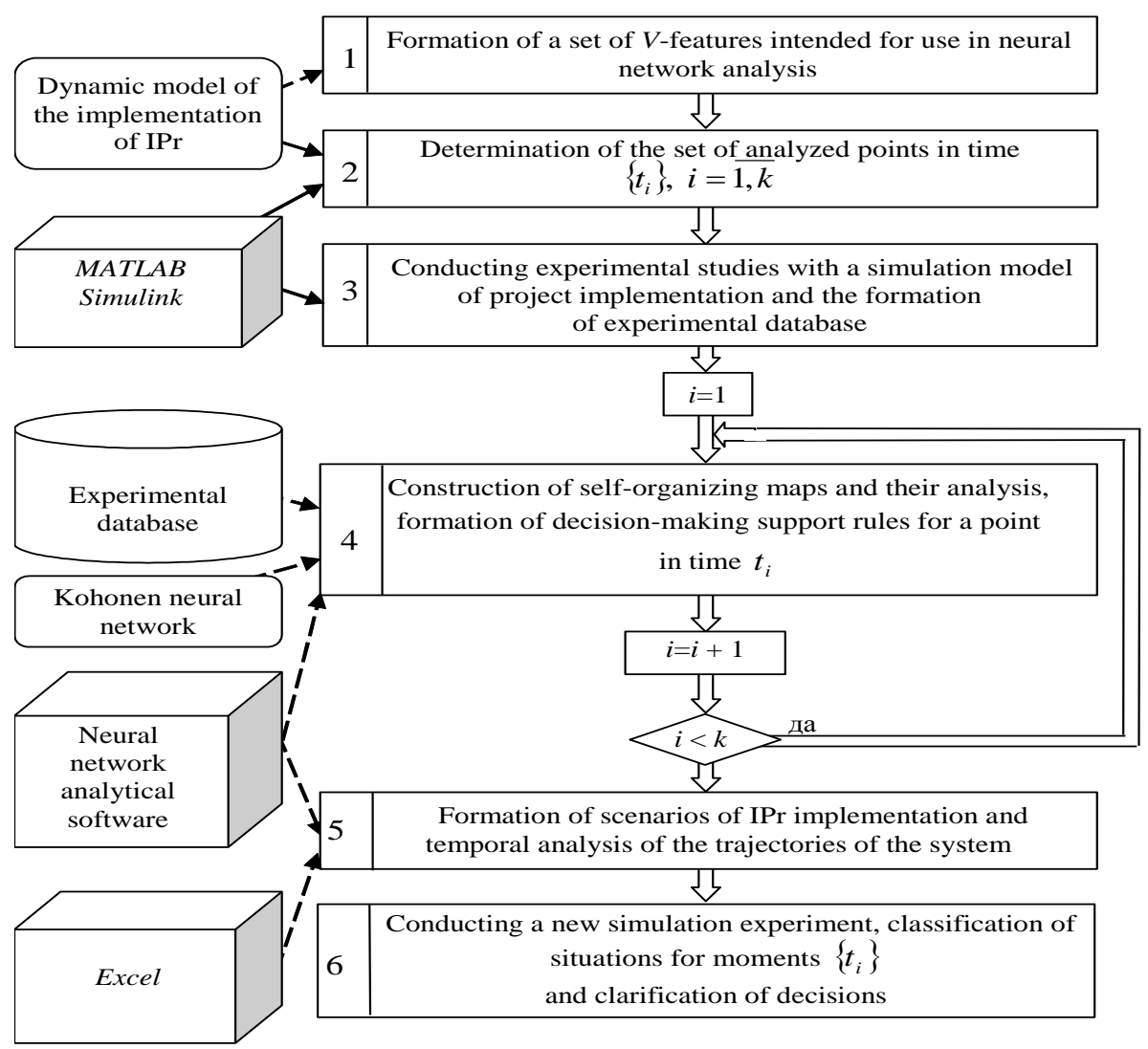

Fig. 2. The generalized scheme of data analysis and decision-making procedures in the management of the investment project

The following five main events are highlighted: the provision of credit and the allocation of funds for investment start of production (point $A$, point in time $\left.t_{A}=8\right)$; start of release of products on investment production (point $B$, point in time $t_{B}=13$ ); the first payment on the loan at the end of the first year of implementation of investments (point $D$, point in time $t_{D}=20$ ); providing return on investment (point $C$, point in time $t_{C}=26$ ); last disbursement on the loan at the end of the period of development of the investment (point $E$, point in time $t_{E}=32$ ). Controlled moments of time are chosen expertly with some lagging behind special events.

In step 3, the experimental data base is being filled in when conducting studies with a dynamic model of investment project implementation. At the same time, for each experiment the data on the state of the object of study are stored in several control moments of time. Note that not only the above vectors of controlled coordinates are used as data on the state of the IPr implementation process, but also additional information in the form of vectors of disturbing effects of $F_{b p}$ on the main production, $F_{i p}$ on the investment production and $F_{\text {ent }}$ for the enterprise as a whole, as well as the vector $Y_{0}$ of planned values of controlled coordinates. Despite the fact that additional information is not used in the training of $\mathrm{NN}$, it is necessary in the subsequent steps in determining the causes of adverse situations in the dynamics for the formation of decision-making rules.
Step 4 is repeated $\mathrm{k}$ times by the number of $\boldsymbol{k}$ controlled moments of time, for each of which, as a rule, a Kohonen network is built.

This is due to the fact that not always the features that are important for neural network analysis at one time interval will be important at another time interval. The scheme of the step 4 is shown in Fig. 4.

In step 4.1, a sample for the $i$-th moment of time is formed upon request to the experimental database. The resulting table contains data on all the parameters of the state of the IPr implementation process.

In step 4.2, the researcher clarifies the set $\mathrm{V}$ by eliminating features that do not have discriminant force, and methods of multivariate statistical analysis can be used; after that, a set of training examples of $V_{t i}$ for the moment $t_{i}$ is finally formed. The estimated number of future clusters $n_{t i}$ is specified.

In step 4.3. the training of Kohonen NN with the help of any software products (Deductor, Viscovery SoMine, NeuroScalp) and the mapping are carried out.

In step 4.4 , the analysis of $\boldsymbol{m}$ Kohonen maps based on $\boldsymbol{m}$ features is carried out. At the same time, the color gamut of features changes within the built clusters on each map is analyzed. According to the quality requirements of clustering, it is necessary that the colors within one cluster are as similar as possible, and between clusters - as different as possible. If this requirement is not met, it is possible to return to step 4.2. In addition, the number of $n_{t i}$ clusters can be 

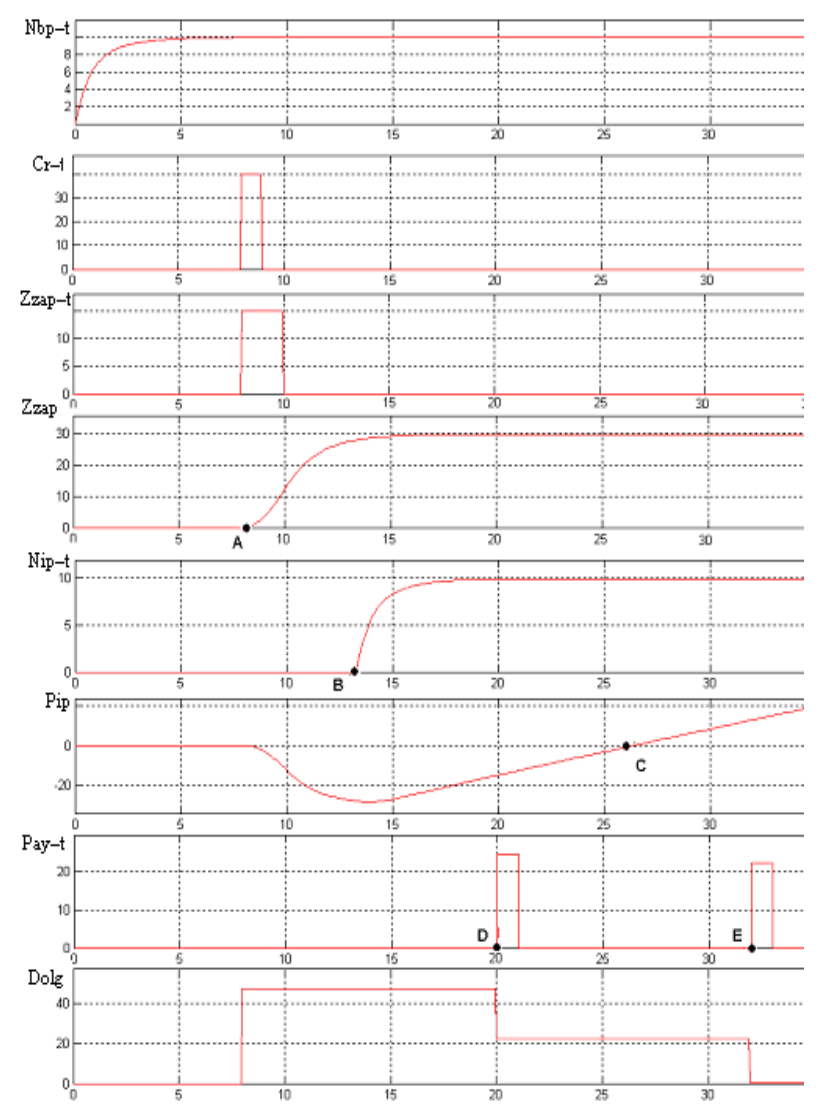

Fig. 3. Schedules of the investment project implementation processes for the basic experiment with indication of special events

varied to obtain a good partition. Based on the results of the SOM analysis, the rules of classification of situations in the class of production models are formulated.

The peculiarity of the proposed neural network technology is to construct scenarios for the implementation of IPr in the form of an integrated trajectory of the system in time, which allows the decision-maker to obtain a generalized evaluation trends in the behavior of the system. This is especially important because it is not possible to analyze a large number of graphs of the coordinates of the process of implementing the IPr in time.

The next two steps (steps 4.5 and 4.6) are designed to accomplish this task. Various procedures are known for studying the dynamics of the system behavior using Kohonen maps. The most common and simple way is to build trajectories of the system in time on the same SOMs. At the same time, moving the state of the system from one cluster to another well interprets the trends of changing situations over time (improvement or deterioration on any grounds). In this case, the trajectory is built by connecting the current situations (map cells) into a single chain. However, this method is applicable only for systems, the composition of the main information features of which does not change over time.

In step 4.7 , the preliminary formation of decisionmaking algorithms for managing the implementation of IPr is carried out. To do this, it is proposed to analyze additional information about the state of the process, that is, signs that did not participate in the training of the NN. The purpose of this analysis is to find the causes of adverse situations for each cluster. As a rule, cluster statistics are used for this purpose. As additional information for the process of implementation of $\operatorname{IPr}$ is considered statistical information on the elements of vectors as disturbing effects of $F_{b p}$ on the main production, $F_{i p}$ on the investment production and $F_{\text {ent }}$ for the enterprise as a whole, and control actions of the lower level of control. Identification of the reasons for the deviation of the current situation from the desired allows to create a variety of solutions that are aimed at eliminating the causes and are presented in the form of indications of qualitative changes in the control coordinates.

In step 5, the trajectories of the system under study are constructed and their time analysis is carried out, which allows to identify the main types of scenarios for the implementation of IPr based on the processing of experimental results.

In step 6 the testing of the proposed $\mathrm{NN}$, classification rules and decision-making when conducting experiments by simulating new situations and building scenarios of IPr is carried out, which allow to give an integrated estimation of development trends of the implementation process of the IPr.

In accordance with the proposed procedure of neural network data analysis and decision-making, the self-organizing maps for five controlled moments of time are constructed in the management of the implementation of the IPr. For each of them, the rules of classification of situations and decision-making are formulated; the main types of scenarios for the implementation of the IPr are identified - pessimistic, optimistic and realistic. According to the results of experimental studies of the effectiveness of management of the implementation of the IPr, the following conclusions were made.

First, the adoption of recommended decisions at an early stage of the project implementation (time period $\Delta t_{1}$ ), associated with the launch of the IP (investment production), allows to prevent subsequent adverse situations associated with a decrease in the efficiency of the implementation of the IPr and non-payment of debt.

Secondly, the effectiveness of the management of the implementation of the IPr (time period $\Delta t_{2}$ ) depends not only on the direction of adjustments of the control coordinates and their values, but also on the time of decision-making and their sequence. 


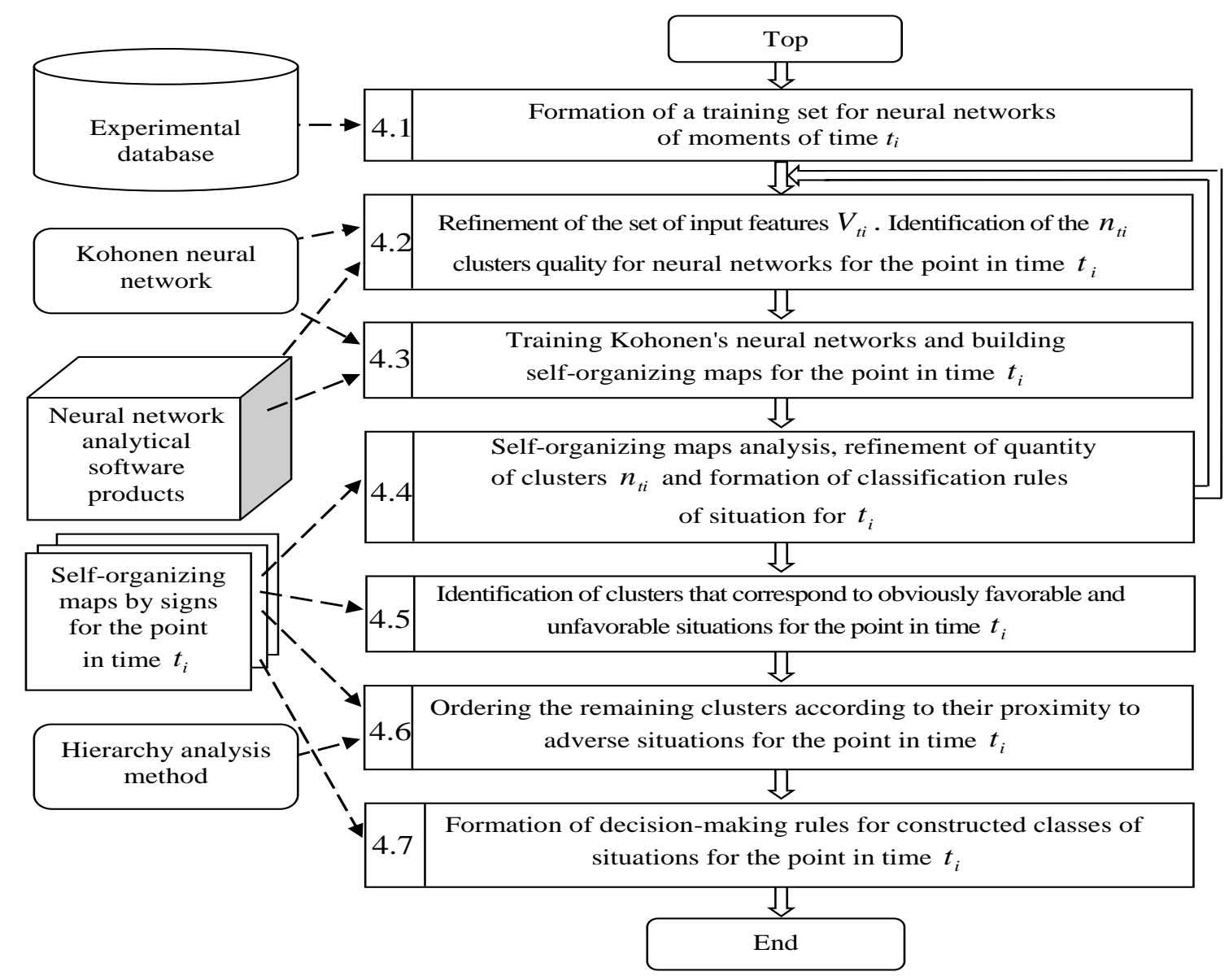

Fig. 4. Scheme of the implementation of step 4 of the construction and analysis of self-organizing maps for the i-th moment of time

Thirdly, it has demonstrated ability of effective management of the process of implementation of IPr at the expense of redistribution of funds between the main production (MP) and the investment production (IP), depending on the market situation of raw materials and products (the time period $\Delta t_{3}$ ). Also it has demonstrated the ability to achieve the planned indicators of efficiency of implementation of IPr due to time savings by reducing the size of current payments and use the savings to stimulate demand in promising areas with the aim of increasing future profits.

Fourthly, the timeliness of decisions will help to ensure the stability of the MP and the IP after the completion of the project (time period $\Delta t_{4}$ ) [13].

The results of experimental studies of the effectiveness of the management of the implementation of the IPr showed that the decisions allow to transform the pessimistic scenarios of the implementation of the IPr into realistic ones, while the rate of profit on the MP increases by 1.2-1.4 times. In case of lack of available funds by redistribution of resources between MP and IP it was proved that efficiency of management of process of implementation of the investment project depends on time of decision-making and their sequence.

\section{CONCLUSION}

The implementation of Russia's Energy strategy for the period up to 2035 is aimed at a gradual increase in investment in the energy sector from $\$ 460$ billion in 2011-2015 up to $\$ 793$ billion in 2031-2035. One of the main conditions is the implementation of investment and innovation development programs.

In early 2020-ies in the energy sector can once again begin the cycle of investment growth in the framework of the program of modernization of TPP and projects of digitalization of the power grids [22]. In this regard, the use of intelligent algorithms in managing the implementation of large-scale investment projects in the fuel and energy complex becomes particularly relevant.

The structure of the system of management of process of IPr implementation including two levels of management is offered. The lower level of management solves the problem, firstly, tactical management of output for the main and investment productions; secondly, adjusting the rate of consumption of resources for production; thirdly, adjusting the loan payments on the basis of information about the accumulated funds. The upper level of control allows to provide support to the decision-maker in decision-making on the formation of the vector of control actions based on the analysis of a large amount of data using neural network 
technologies. The procedure of neural network data analysis and decision-making for the management of the implementation of IPr based on the development of Kohonen networks and construction of selforganizing maps maps is developed. The considered pessimistic and realistic scenarios demonstrated the possibility of effective management of the studied process through the redistribution of funds between the main and investment production, depending on the situation in the markets of raw materials and products, as well as the possibility of achieving the planned performance through savings by reducing the amount of current payments and the use of savings to stimulate demand in promising areas in order to increase future profits In addition, it is shown that the timeliness and the correct sequence of decision-making in time allows for greater profits, and therefore, the stability of the functioning of the main and investment productions after the completion of the development of investments.

The developed models, algorithms and software of IAMS management of large investment projects can be used both as an adviser to the decision-maker in the formation of effective management decisions, and for training specialists in the field of real investment management, as well as for various types of experimental studies of the studied process.

\section{ACKNOWLEDGMENT}

The work is executed at support of the RFBR (Russian Foundation for Basic Research) grant No. 17-08-01155 A "Intelligent decision-making support in the management of diversified industrial complex as multi-variable dynamic object on the basis of neural network and simulation modeling".

\section{REFERENCES}

[1] Investments in the FEC: growth after the crisis on the oil market. Energy Bulletin June 2018, № 61. Analytical center under the Government of the Russian Federation. URL:// http://ac.gov.ru/publications/bulletin/ (date of the application: 2.03.2019). (in Russian).

[2] Energy strategy of Russia for the period up to 2035 (main provisions). URL: http://ac.gov.ru/files/content/1578/11-0214-energostrategy-2035-pdf.pdf (date of the application: 2.03.2019). (in Russian).

[3] Results of 2018 and prospects of development of electric power industry of the Russian Federation. URL: https://marketing.rbc.ru/articles/10691/ (date of the application: 2.03.2019). (in Russian).

[4] T.V. Uskova, On the role of investment in ensuring sustainable economic growth. Economic and Social Changes: Facts, Trends, Forecast, 2013, № 6 (30), pp. 45-59. URL: http://esc.vscc.ac.ru/article/464 (date of the application: 2.03.2019). (in Russian).

[5] S. Yu. Glazyev, A. E. Ajvazov, and V. A. Belikov, The Future of the World Economy Is an Integrated World Economic Structure. Economy of Region, 2018, 14(1), pp. 112. (in Russian).

[6] E. V. Butsenko, Optimization of Investment Planning Based on Game-Theoretic Approach. Economy of Region, 2018, 14(1), pp. 270-280. (in Russian).

[7] S. N. Silvestrov, V. P. Bauer, and V. V. Eremin, Estimation of the Dependence of the Investment Multiplier on the Structure of the Regional Economy. Economy of Region, 2018, 14(4), pp. 1463-1476. (in Russian).
[8] A. L. Novoselov, I. M. Potravny, I. Yu. Novoselova, and K. Y. Chávez Ferreyra, The Mechanism to Implement Environmental Investment Projects on the Basis of Equity Financing. Economy of Region, 2018, 14(4), pp. 1488-1497. (in Russian).

[9] C.-H. L. Lee, A. Liu, A Financial Decision Supporting System Based on Fuzzy Candlestick Patterns. 9th Joint International Conference on Information Sciences. Atlantis Press. (October 2006), https://doi.org/10.2991/jcis.2006.58

[10] M. Mitchell. Complex systems: Network thinking. Artificial Intelligence, vol. $170 \quad$ (2006), pp.1194-1212. doi:10.1016/j.artint.2006.10.002.

[11] L.Hongjiu, R.Rieg, H.Yanrong. Performance comparison of artificial intelligence methods for predicting cash flow. Neural Network World, vol. 6, 2012, pp. 549-564. https://doi.org/ 10.14311/NNW.2012.22.034.

[12] S.-S. Hung, D.Sh.-M. Liu. A Framework for Knowledgebased Management Model on Decision-Making. 9th Joint International Conference on Information Sciences. Atlantis Press. (October 2006), https://doi.org/10.2991/jcis.2006.116.

[13] B. G. Ilyasov, E. A. Makarova, and G. A. Zimina, Management of investment projects implementation on the basis of simulation modeling methods and neural network technologies. Ufa Gilem, 2010, 240 p. (in Russian).

[14] G. A. Zimina, I. O. Kudryashov, and A. S. Shpak, Development of accounting and control system for the implementation of investment projects with state participation. Scientific and educational journal "The genesis of genius"; Geneva, Switzerland, December 2016, № 7. Publishing Center of The international scientific association of economists and jurists "Consilium", Geneva, 2016, 221 p. (in Russian).

[15] E. A. Makarova, and G. A. Zimina, Methodology of research and modeling of the dynamics of the investment project implementation. Mechatronics, automation, management, 2007, no. 9, pp. 32-36. (in Russian).

[16] Ch.-H. Shih, S.-J. Lin, M.-F. Hsu. Detection of financial information manipulation by an ensemble-based mechanism. Neural Network World, vol. 5, 2014, pp. 479-499. doi: 10.14311/NNW.2014.24.028.

[17] M. Taieb-Maimon, L. Limonad, D. Amid, D. Boaz, A. Anaby-Tavor. (2013) Evaluating Multivariate Visualizations as Multi-objective Decision Aids. In: Kotzé P., Marsden G., Lindgaard G., Wesson J., Winckler M. (eds) HumanComputer Interaction - INTERACT 2013. INTERACT 2013. Lecture Notes in Computer Science, vol 8117. Springer, Berlin, Heidelberg. https://doi.org/10.1007/978-3-642-404832_29.

[18] D. Plikynas, R. Aleksiejūnas. Neural Network Based Multiagent System for Simulation of Investing Strategies. In: Klusch M., Hindriks K.V., Papazoglou M.P., Sterling L. (eds) Cooperative Information Agents XI. CIA 2007. https://doi.org/10.1007/978-3-540-75119-9_12.

[19] V. Chaudhary, R. S. Bhatia, and A. K. Ahlawat, An efficient self-organizing map (E-SOM) learning algorithm using group of neurons. International Journal of Computational Intelligence Systems, Atlantis Press, vol. 7, no. 5 (October 2014), pp. 963-972. https://doi.org/10.1080/18756891. 2014.966995 .

[20] Y. Erzin, M. Nikoo, M. Nikoo, T. Cetin. The use of selforganizing feature map networks for the prediction of the critical factor of safety of an artificial slope. Neural Network World vol. 5, 2016, pp. 461-475. DOI: 10.14311/NNW.2016.26.027.

[21] J. Anitha, D. Jude Hemanth. An efficient kohonen-fuzzy neural network based abnormal retinal image classification system. Neural Network World, vol. 2, 2013, pp. 149-167. DOI: 10.14311/NNW.2013.23.011.

[22] «10+10»: energy industry of the Russian Federation in anticipation of a new reform to exit the investment pause. Russian electrical energy industry: forecast until 2022. URL://https://www.acra-ratings.ru/research/691 (date of the application: 2.03.2019). (in Russian). 